\title{
Aplicação de simuladores de eventos discretos no processo de modelagem de sistemas de operações de serviços
}

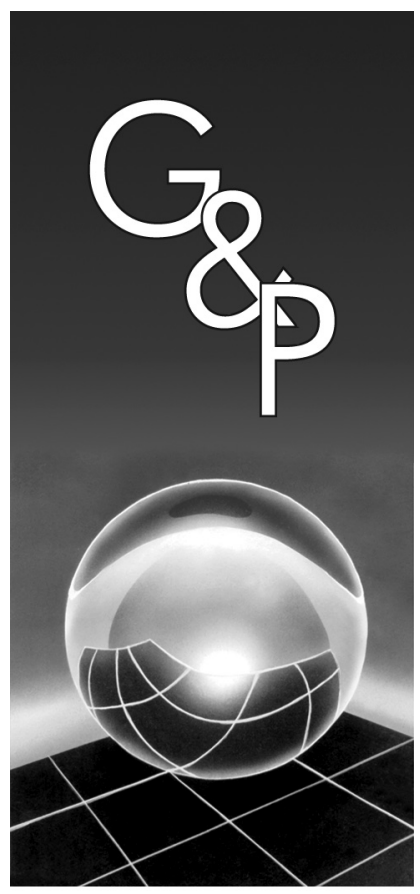

Nelson Sakurada

Dario Ikuo Miyake

Resumo

O presente trabalho discute a aplicação da simulação no estudo de sistemas de operação de serviços. Como objetos de estudo, são analisados tipos de serviços classificados como "Lojas de Serviços" e "Serviços de Massa". O trabalho inclui uma definição dos requisitos dos usuários para os softwares de simulação aplicáveis na modelagem e simulação de sistemas de operação de serviços, avalia a aplicação de dois simuladores disponíveis no mercado e analisa como o processo de modelagem varia de acordo com o tipo de serviço analisado. Ao final do trabalho, conclui-se que o desenvolvimento da tecnologia de simulação bem como os softwares de simulação em si, ainda precisam evoluir até incorporarem a capacidade de representar uma gama mais completa de elementos e relações envolvidos em processos de serviço, que não são presentes em aplicações convencionais da simulação no âmbito dos sistemas de manufatura.

Palavras-chave: Serviços. Simulação de eventos discretos. Processo de modelagem.

\section{Introdução}

A simulação é uma técnica utilizada tanto para projeto e avaliação de novos sistemas, como para reconfiguração física ou mudanças no controle e/ou regras de operação de sistemas existentes. As suas aplicações têm crescido em todas as áreas, auxiliando os gestores na tomada de decisão em problemas complexos e possibilitando um melhor conhecimento dos processos nas organizações.

A grande variedade de softwares de simulação disponíveis no mercado, alguns específicos para determinados processos, outros de caráter mais generalista, favorecem a aplicação da simulação de uma forma geral. A competição entre as empresas fabricantes de softwares de simulação tem impulsionado o lançamento de "pacotes" cada vez mais poderosos que oferecem novas facilidades tais como ferramentas de suporte ao processo de modelagem, recursos de análise estatística e interfaces gráficas intuitivas (user-friendly).

Dado que a técnica de simulação pode ser aplicada aos mais variados tipos de sistemas, este artigo considera a sua aplicação na Simulação de Eventos Discretos (SED) e Estocásticos, em que o estado do sistema muda discretamente no tempo - não de forma contínua - e o comportamento não obedece a um padrão determinístico de entradas e saídas, mas aleatório, geralmente caracte- rizado por uma distribuição probabilística que melhor representa o fenômeno real estudado.

A tendência de crescimento do setor de serviços nos cenários nacional e mundial, aliada à complexidade geralmente atribuída a esses sistemas, tem estimulado a realização de pesquisas sobre a aplicação da simulação como técnica de suporte ao seu desenvolvimento. No entanto, os estudos de aplicação da simulação no setor de serviços, quando comparados em número aos trabalhos publicados sobre aplicações em manufatura e logística, ainda são poucos e direcionados a organizações em segmentos específicos como saúde (MACHUCA et al., 2007; WHITE, 2005; GIACHETTI et al., 2005) e call centers (TANIR; BOOTH, 1999; KLUNGLE, 1999; SALTZMAN; VIJAY, 2001).

Com base em um estudo dos principais periódicos sobre gestão de operações nos últimos 30 anos, Shafer e Smunt (2004) evidenciaram a baixa quantidade de publicações que abordam a aplicação de técnicas de simulação para avaliação de níveis de serviço e a capacitação/flexibilidade de recursos humanos.

Diante deste panorama, urge explorar o potencial de aplicação da técnica de simulação no setor de serviços, 
promovendo uma discussão do processo de modelagem em que são definidos os elementos de um sistema e suas respectivas inter-relações.

\section{Objetivos}

Os principais objetivos do presente trabalho são definidos a seguir:

a) Delinear as características do processo de modelagem de sistemas de operação de serviços que se enquadram como Lojas de Serviços e Serviços de Massa. Para isso, o trabalho parte da identificação das principais características dos tipos de serviço focados para, então, investigar como elas podem influenciar o processo de modelagem.

b) Definir requisitos para modelagem de sistemas de operação de serviços enquadrados como Lojas de Serviços e Serviços de Massa. Isso implica em identificar os principais elementos e dimensões do sistema de serviço objeto de estudo que devem ser representados quando da programação de um modelo de simulação.

Apoiando-se nos conceitos pesquisados e organizados a partir da consideração destes objetivos primários, o trabalho avalia também o potencial de aplicação de ferramentas de simulação disponíveis no mercado para novas aplicações de modelagem no setor de serviços.

\section{Simulação de sistemas}

Winston (1993) define que um sistema é um conjunto de entidades que agem e interagem com um determinado propósito. Observando que fatores externos podem afetar este sistema, a fronteira de estudo deve ser delimitada pelo modelador de acordo com sua finalidade. As diferentes abordagens possíveis para se desenvolver estudos de sistemas são relacionadas por Law e Kelton (1991) e Winston (1993) podendo ser organizadas conforme a Figura 1. A simulação abordada neste trabalho é uma das técnicas que podem ser utilizadas quando o estudo se baseia em experimentos realizados com um modelo do sistema objeto de estudo e a complexidade do sistema real torna inviável a utilização de métodos matemáticos de solução analítica, tais como cálculo diferencial, teoria de probabilidade, métodos algébricos e teoria de filas (BANKS et al.,1996).

Um modelo pode ser definido como "uma representação externa e explícita de parte da realidade vista pela pessoa que deseja usar aquele modelo para entender, mudar, gerenciar e controlar parte daquela realidade" (PIDD, 1996). Como salientam Banks et al. (1996), apesar de um modelo ser uma representação simplificada de um sistema em estudo, deve conter detalhamento suficiente para que possa ser utilizado como uma representação válida.

\subsection{Simulação de eventos discretos}

A simulação de eventos discretos abrange o estudo de modelos de simulação cujas variáveis mudam de estado instantaneamente em pontos específicos de tempo, em contraste ao que ocorre com modelos contínuos, cujas variáveis podem mudar de estado continuamente no decorrer do tempo. Gordon (1978), Law e Kelton (1991) atentam para o fato que poucos sistemas, na prática, são totalmente discretos ou totalmente contínuos, sendo comum durante a modelagem considerar o modo predominante de ocorrência dos eventos no sistema.

Segundo Borshchev e Filippov (2004), simulações de eventos discretos abrangem sistemas com médio a alto nível de detalhamento (Figura 2), sendo geralmente aplicadas para modelagem de sistemas com baixo nível de abstração, diferentemente da Dinâmica de Sistemas que é uma metodologia de simulação utilizada em modelagem de sistemas agregados, em nível estratégico. Nesses sistemas, os indivíduos (entidades) não precisam ser altamente diferenciados e uma representação em nível agregado é considerada por exemplo na modelagem de uma população ou um sistema econômico (SIEBERS et al., 2007).

\subsection{O processo de modelagem em simulação}

Partindo do princípio que não existem modelos ideais que representem os sistemas para fins de estudos gerenciais, Rivett (1980) observa que a forma de representação de um sistema é, primeiramente, uma ciência subjetiva. Isso ocorre porque a compreensão do sistema e a identificação de seus elementos mais significativos - incluindo suas relações de interdependência - dependem do conhecimento, da experiência e da habilidade do modelador.

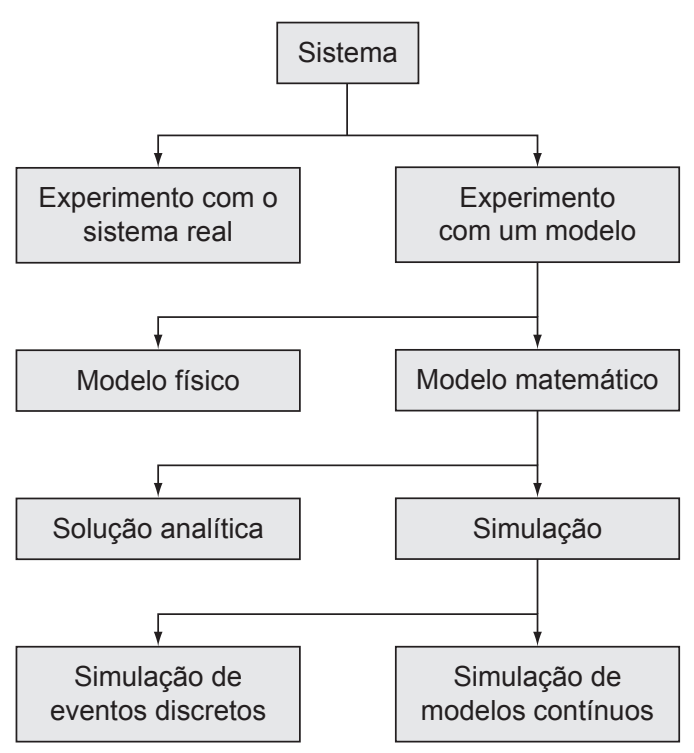

Figura 1. Abordagens para a realização de estudos de sistemas. Adaptada de Law e Kelton (1991), Winston (1993). 
O processo de modelagem deve inicialmente buscar uma clara compreensão da estrutura e dinâmica do sistema real a ser simulado e somente então avançar para a derivação dos procedimentos experimentais que possibilitarão analisar seu comportamento. Neste artigo, com base nas perspectivas de Shannon (1975), Winston (1993) e Banks et al. (1996), serão focadas as fases de Formulação do Modelo Conceitual, Coleta de Dados e Programação do Modelo, os quais se inserem num contexto mais amplo de desenvolvimento de um estudo de simulação tal como apresentado na Figura 3.

A Formulação do Modelo Conceitual compreende o levantamento de suposições sobre os componentes do sistema, a estrutura do sistema (inclusive as interações entre os componentes) e as hipóteses sobre os parâmetros e variáveis envolvidas.

Apesar da fase de Coleta de Dados estar representada na Figura 3 como parte do processo de Programação do Modelo, não é possível dissociá-la da Formulação do Modelo Conceitual, pois é com base nas informações obtidas que as hipóteses e relações iniciais são incorporadas ao modelo. Os dados coletados devem representar bem o comportamento do sistema real não apenas para que a formulação do modelo em si seja bem embasada, mas também porque eles são utilizados na fase posterior de Validação.

A Programação do Modelo envolve a codificação dos dados e relações previamente levantados por meio de um

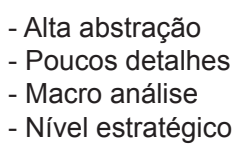

- Média abstração

- Médios detalhes

- Meso cenários

- Nível tático

- Baixa abstração

- Muitos detalhes

- Micro análise

- Nível operacional

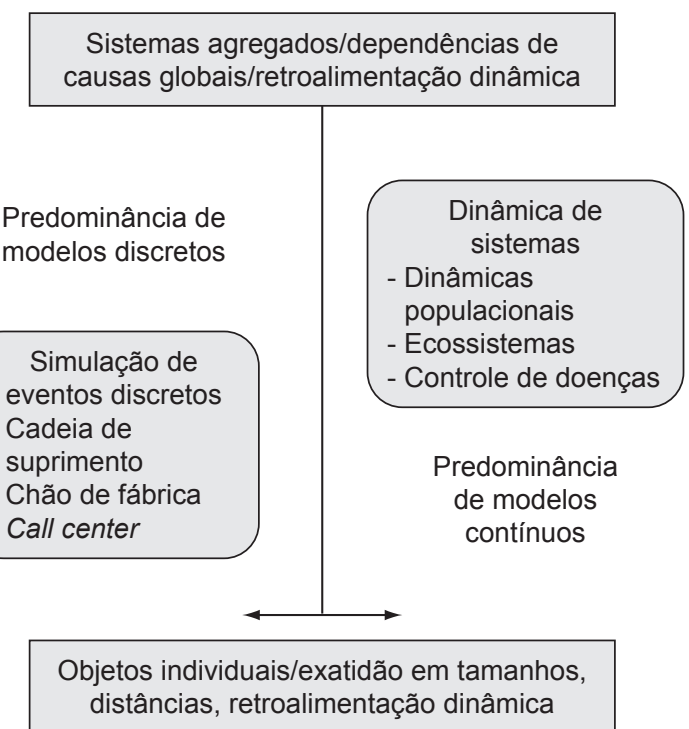

Objetos individuais/exatidão em tamanhos,

Figura 2. Abordagens de simulação e níveis de abstração dos sistemas. Adaptado de Borshchev e Filippov (2004).

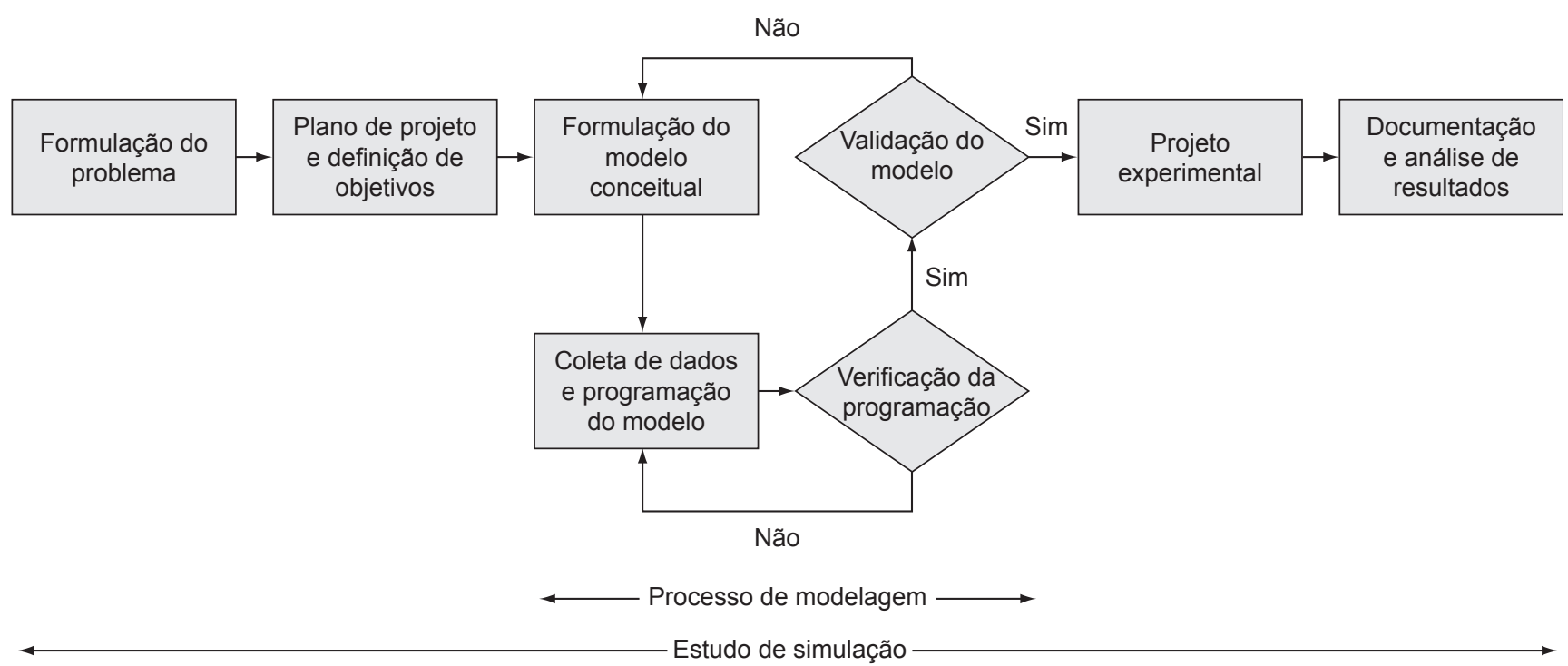

Figura 3. Processo de modelagem num estudo de simulação. Adaptada de Shannon (1975), Winston (1993) e Banks et al. (1996). 
software de simulação apropriado ou uma linguagem de programação (ex: C++, Java). Esta fase deve ser combinada com a realização de testes para Verificação tanto de erros de programação (debug) quanto de funcionamento do modelo computadorizado.

A Validação do Modelo também não pode ser dissociada do processo de modelagem, pois, nesta fase, sua aderência e representatividade frente ao sistema em estudo são testadas comparando-se os resultados simulados com os dados reais obtidos na coleta de dados.

\subsection{Softwares de simulação}

Os softwares de simulação podem ser basicamente agrupados em duas grandes categorias, quais sejam, "linguagens de simulação" e "simuladores" (LAW; KELTON, 1991). As linguagens de simulação são "pacotes" computacionais de natureza genérica, porém com características especiais para determinados tipos de aplicação da simulação. Uma das principais vantagens das linguagens de simulação é que oferecem suficiente abertura para gerar modelos de simulação para os mais variados tipos de sistema. As desvantagens estão associadas à necessidade de conhecimentos bastante específicos de programação para a construção de modelos mais complexos. Já os simuladores oferecem vantagens como requerimento de tempo relativamente menor para construção do modelo e maior facilidade de utilização apoiada em menus e gráficos amigáveis (user-friendly). Por outro lado, os simuladores revelam desvantagens como menor flexibilidade para representar detalhes do sistema real e restrições para controlar a realização de experimentos sob condições muito específicas.

Neste trabalho, com o propósito de avaliar o potencial de aplicação de simuladores na modelagem e simulação de sistemas de operação de serviços, as seguintes ferramentas de simulação foram selecionadas: Arena 5.0 da Rockwell Softwares e ProModel 4.22 da ProModel Corporation. Estas ferramentas têm encontrado crescente receptividade, tanto no meio acadêmico como empresarial, notadamente para aplicações em sistemas de manufatura, movimentação e armazenagem de materiais.

No processo de modelagem usando o simulador Arena, o modelo é estruturado e codificado com base na linguagem de simulação SIMAN por meio da seleção dos módulos que contêm as características dos processos a serem modelados. O modelador não precisa necessariamente conhecer esta linguagem para construir um modelo, pois, utilizando os modelos disponibilizados pelo Arena, o usuário pode extrair módulos, posicioná-los no modelo e parametrizá-los de acordo com as características observadas no sistema real.

O ProModel é um simulador cujas aplicações se desenvolveram inicialmente na simulação de sistemas de manufatura, mas sua flexibilidade de programação permitiu estender sua aplicação a outros tipos de sistemas de operação tais como cadeias de suprimento, organizações administrativas e sistemas de serviço na área de saúde. Oferece funcionalidades que facilitam, por exemplo, a programação por meio de uma interface simples, o controle do avanço do tempo simulado com noção do calendário e turnos de trabalho, e a realização de análises estatísticas.

\section{Sistemas de operação de serviços}

No estudo da produção de um serviço, é fundamental observar que o processo não só cria o produto como também o entrega ao cliente. Além disso, há sistemas de prestação de serviço que incluem a participação do próprio cliente no processo. Tais aspectos fazem com que os sistemas de serviço possam ser classificados em função de quatro dimensões-chave, quais sejam: intangibilidade, perecibilidade, variabilidade e simultaneidade da produção e consumo (GIANESI; CORRÊA, 1994).

A distinção entre bens e serviços pode ser aparentemente fácil, porém vale salientar que na realidade em muitos sistemas há uma combinação de ambos nos processos de produção de bens ou serviços. Sasser et al. (1978) consideram que a melhor maneira de entender o conceito de um serviço é avaliar os componentes que são percebidos pelo consumidor que recebe o serviço e pelo vendedor/provedor que o fornece. Para estes autores, três aspectos inerentes à prestação de serviços devem ser observados, quais sejam: 1) itens físicos que permitem que o serviço seja realizado (chamados de bens facilitadores); 2) os benefícios sensoriais ou serviços explícitos; e 3) os benefícios psicológicos ou serviços implícitos.

Apesar da enorme diversidade de serviços atualmente oferecidos aos consumidores, eles podem ser agrupados em determinadas categorias de sistema de serviços que facilitam seu tratamento. No presente trabalho, adotou-se o critério de classificação de sistemas de serviços apresentado nos estudos de Silvestro (1999) e Corrêa e Caon (2002) que sugerem os seguintes três tipos básicos:

a) Serviços profissionais: São caracterizados por uma intensa participação do cliente no processo de prestação do serviço, o que demanda uma grande flexibilidade do sistema para atender suas necessidades específicas. Os recursos humanos geralmente apresentam alta qualificação e oferecem um atendimento bastante personalizado, realizando tarefas com baixa especificação e repetitividade. Um exemplo de serviço profissional é a realização de projetos com prazo determinado para finalização e alto grau de customização. 
b) Serviços de massa: De forma geral, a especificação deste tipo de serviço já está bem definida antes do cliente entrar no processo. A formatação deste tipo de serviço se apóia num elevado grau de padronização e rotinização baseado em pesquisas sobre expectativas dos clientes. $\mathrm{Na}$ organização dos recursos humanos, há uma tendência à divisão do trabalho e à especialização de tarefas para atender a uma demanda em alta escala com eficiência. Isso também pode justificar investimentos para substituição dos recursos humanos por equipamentos e/ou sistemas informatizados.

c) Lojas de Serviços: Tipo definido como intermediário entre Serviços Profissionais e Serviços de Massa. Podem ser enquadrados nesta classificação, diversos sistemas de serviços encontrados em estabelecimentos como hotéis, restaurantes, lavanderias e hospitais.

A Figura 4 ilustra como estes 3 tipos se caracterizam em função do volume de clientes atendidos e das seguintes dimensões: grau de customização do serviço, tipo de recurso mais empregado, ênfase do processo e intensidade de contato com o cliente.

No presente trabalho, não se considerou a modelagem da prestação de Serviços Profissionais pelo elevado grau de particularidade de seus casos de atendimento e por constituírem tipicamente operações de baixo volume. Estes aspectos limitam a utilidade da aplicação da simulação de eventos discretos para estudar a racionalidade de seu sistema de operações.

\section{Estrutura conceitual para modelagem de operações de serviço}

Nesta seção, é apresentada a estrutura conceitual em que se apoiou o estudo de avaliação do processo de modelagem de sistemas de serviços.

Quando o objeto de estudo é um sistema de serviço, é importante que o modelador atente aos aspectos mais relevantes a sua compreensão e caracterização sob a ótica da gestão de serviços. Para orientar a fase de Formulação do Modelo Conceitual, foram identificados e relacionados no Quadro 1 os elementos fundamentais na definição de sistemas de serviço apontados na literatura..

Ainda no Quadro 1, a natureza dos elementos/dimensões identifica como um serviço pode se posicionar no seu espectro de variação; sugerindo ao modelador que o objeto de estudo pode ser enquadrado entre situações extremas diametralmente opostas. Ao avaliar, por exemplo, o grau de influência do cliente no processo admitido pelo serviço, o modelador deve considerar que, dependendo do conceito de serviço oferecido ou de decisões do gestor, pode variar de baixo a alto. Analogamente, a natureza da organização de recursos humanos pode variar desde a rigidez do trabalho numa linha de produção até a variabilidade de tarefas que é inerente ao trabalho baseado em times.

A consideração de tais elementos/dimensões é importante para se avaliar o grau de flexibilidade de um software de simulação para a modelagem de diferentes sistemas de operação de serviços.

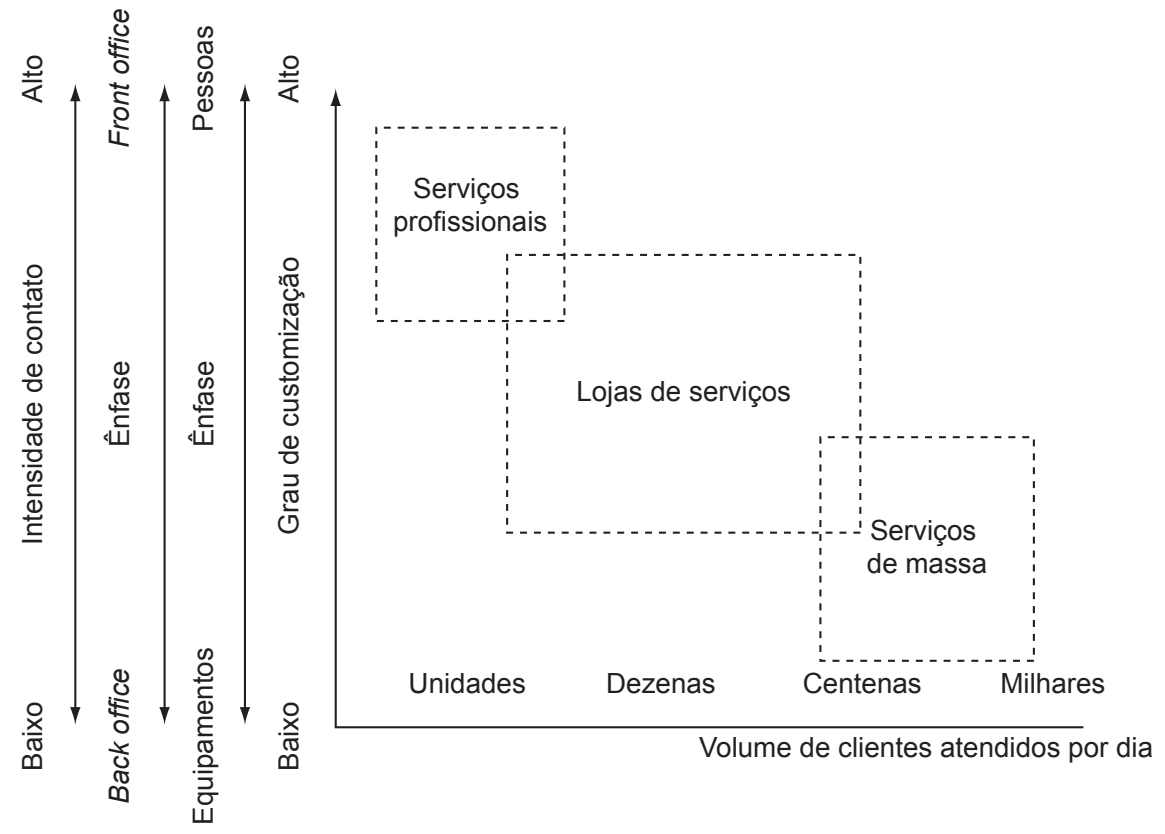

Figura 4. Classificação de Serviços. Adaptada de Silvestro, 1999; Correa e Caon, 2002. 
Quadro 1. Elementos a serem considerados na formulação do modelo conceitual.

\begin{tabular}{|c|c|c|}
\hline Dimensões & Análise & Referências \\
\hline $\begin{array}{l}\text { Serviços oferecidos } \\
\text { para o cliente }\end{array}$ & $\begin{array}{l}\text { Único } \sim \text { diversificado } \\
\text { (volume } x \text { customização) }\end{array}$ & $\begin{array}{l}\text { (CORRÊA; CAON, 2002; SILVESTRO, 1999; FITZSIMMONS; } \\
\text { FITZSIMMONS, 2000; SLACK, 1997) }\end{array}$ \\
\hline Cliente & $\begin{array}{l}\text { Presença do cliente (in loco } \sim \\
\text { remota); influência no processo } \\
\text { (baixa influência alta influência) }\end{array}$ & $\begin{array}{l}\text { (SHOSTACK, 1987; LOVELOCK, 1996; CORRÊA; CAON, 2002; } \\
\text { FITZSIMMONS; FITZSIMMONS, 2000) }\end{array}$ \\
\hline $\begin{array}{l}\text { Organização dos } \\
\text { recursos humanos }\end{array}$ & $\begin{array}{l}\text { Linha de produção organização } \\
\text { baseada em equipes }\end{array}$ & (BOWEN; LAWLER, 1995) \\
\hline Ênfase das operações & Back Office Front Office & (CORRÊA; CAON, 2002) \\
\hline Volume de clientes & Unidades $\sim$ milhares & (SILVESTRO, 1999; CORREAA; CAON, 2002) \\
\hline Intangibilidade & Objetiva $\sim$ perceptiva & $\begin{array}{l}\text { (SASSER et al., 1978; FITZSIMMONS; FITZSIMMONS, 2000; } \\
\text { KOTLER, 2000; CORRÊA; CAON, } 2002 \text {; JOHNSTON; CLARK, 2002) }\end{array}$ \\
\hline $\begin{array}{l}\text { Simultaneidade/ } \\
\text { perecibilidade }\end{array}$ & Ocorrência de filas/espera & $\begin{array}{l}\text { (SASSER et al., 1978; FITZSIMMONS; FITZSIMMONS, 2000; } \\
\text { KOTLER, 2000; CORRÊA; CAON, } 2002 \text {; JOHNSTON; CLARK, 2002) }\end{array}$ \\
\hline Variabilidade & Natureza estocástica do sistema & $\begin{array}{l}\text { (SASSER et al., 1978; FITZSIMMONS; FITZSIMMONS, 2000; } \\
\text { KOTLER, 2000; CORRÊA; CAON, } 2002 \text {; JOHNSTON; CLARK, 2002) }\end{array}$ \\
\hline
\end{tabular}

A fase da Coleta de Dados de um sistema real é sempre uma fase crítica para a simulação (BANKS et al., 1996). Isso porque é uma atividade que requer tempo e comprometimento das partes envolvidas. A construção de um modelo para sistemas de operação de serviço requer dados dos seguintes tipos básicos: 1) demanda, 2) configuração e dimensões da infraestrutura física, 3) tempos de serviço. Trata-se de dados quantitativos que podem ser extraídos de relatórios e documentos existentes ou que terão de ser levantados em campo pelo modelador. Destes três tipos de dados, o terceiro comumente requer especial atenção, pois dificilmente são encontrados na forma requerida pelo modelo e os tempos de operação precisam ser caracterizados para cada atividade que for nele incorporada.

Para orientar a coleta deste tipo de dados e garantir sua consistência, dentre as técnicas de Estudo de Tempos existentes, neste trabalho foi considerada a aplicação de duas técnicas fundamentais para medição direta do trabalho: Cronometragem e Amostragem do Trabalho.

A Cronometragem envolve a identificação e a medição dos elementos de movimento que constituem uma tarefa altamente repetitiva. As medições são feitas com um cronômetro e os tempos de duração dos ciclos de movimentos elementares são registrados em uma folha de observações (FITZSIMMONS; FITZSIMMONS, 2000). Já a Amostragem do Trabalho é uma técnica utilizada para se determinar como as pessoas dividem o seu tempo entre vários tipos de atividades. Esta técnica é aplicada quando um trabalhador desempenha uma combinação de atividades pouco estruturadas e sujeitas à aleatoriedade, pois se preocupa com a proporção de tempo que um trabalhador fica ocupado em cada tipo de atividade e não com o tempo gasto no desempenho de tarefas repetitivas e bem definidas. Segundo Fitzsimmons e Fitzsimmons (2000), esta técnica é muito útil no projeto e reprojeto de tarefas do pessoal de front office, devido à natureza não programada das atividades de contato direto com o cliente.

Finalmente, a execução da Programação do Modelo pode ser orientada e organizada tomando-se como referência a relação genérica dos componentes fundamentais de um programa de simulação proposta por Banks et al. (1996), que se mostra adequada também para a consideração de sistemas de operação de serviços. Os principais componentes nos quais o programador deve atentar para fins de codificação são enumerados a seguir:

a) Elementos básicos: Qualquer objeto ou componente relevante do sistema objeto de estudo que requer representação explícita no modelo de simulação (ex: funcionário, cliente, máquina, etc.);

b) Atributos: Propriedades das entidades (ex: tipo de cliente, tipo de pedido);

c) Filas: Coleções de entidades em estado de espera, ordenadas de acordo com alguma lógica (ex: FIFO, LIFO);

d) Eventos: Ocorrências que alteram o estado do sistema considerado (ex: chegada de um cliente);

e) Atividades: Ações que duram um tempo definido (ex: tempo de atendimento), de maneira determinística, estocástica ou através de uma função que 
depende das variáveis do sistema ou atributos de entidades;

f) Movimentações: Roteamentos das entidades e recursos móveis no sistema.

\section{Exemplos de processo de modelagem de serviços}

Para o estudo empírico do processo de modelagem de serviços, foram considerados dois exemplos reais de serviços típicos existentes em universidades: uma biblioteca e um restaurante universitário. O sistema de operação do primeiro pode ser enquadrado como Loja de Serviços e o do segundo como Serviço de Massa. No desenvolvimento do processo de modelagem dos dois sistemas objetos de estudo, procurou-se identificar as principais características dos serviços oferecidos e como estas influenciam o processo de modelagem nas três fases que constituem o foco deste trabalho.

\subsection{Formulação do modelo conceitual para os sistemas de serviço considerados}

A formulação do modelo partiu da observação direta dos sistemas objetos de estudo visando a caracterizar a dinâmica de suas operações e a organização de seus recursos. Para os dois objetos de estudo, a fronteira do modelo a ser formulado foi limitada às atividades do serviço de atendimento ao público. Isso implicou não abranger as atividades de back-office não relacionadas à entrega de serviços aos clientes presentes nem $\mathrm{o}$ funcionamento do sistema antes e depois do horário de atendimento.

Considerando inicialmente a natureza do(s) serviço(s) prestado(s), notou-se que na biblioteca os serviços oferecidos são mais diversificados se comparados ao do restaurante universitário, sendo que na primeira, além do cliente poder escolher o(s) serviço(s) que busca, pode ter seu atendimento realizado com certo grau de personalização. Já no restaurante universitário, os clientes ainda que tenham perfis distintos, recebem basicamente $o$ mesmo serviço e participam do processo da forma mais passiva.

Uma vez identificado(s) o(s) serviço(s) disponíveis nos sistemas estudados, suas operações devem ser caracterizadas. Na biblioteca, não há uma sequência definida de atividades que o cliente pode solicitar a um atendente (ex. no balcão) ou realizar autonomamente (ex. acesso ao acervo, consulta por computador). Isso implica em uma alta complexidade do conjunto de possíveis fluxos que os clientes podem seguir em suas instalações. Por outro lado, o restaurante universitário estabelece uma sequência bem definida de atividades desde a entrada do cliente até sua saída. São poucas as escolhas que o cliente pode fazer no sistema (ex: escolha de um dos dois balcões de atendi- mento, escolha da mesa) e estas, em geral, pouco afetam o processo produtivo. As atividades de front office no restaurante universitário podem ser facilmente descritas pela figura de uma linha de produção devido ao seu fluxo ser bem definido e sujeito a poucos momentos de decisão, enquanto no caso da biblioteca, pode haver um único fluxo de chegada de clientes, mas este se ramifica em vários modos de serviço.

Em relação à organização dos sistemas considerados, na biblioteca, os recursos humanos desempenham diversas atividades, abrangendo tanto o front office como o back office e sua movimentação no sistema varia muito de acordo com a(s) atividade(s) solicitada(s). Já no restaurante universitário, os recursos humanos que atuam no front office realizam atividades bastante especializadas (menor diversidade) de forma muito mais repetitiva podendo-se admitir que durante o atendimento seus movimentos são limitados na região de seus postos de trabalho.

\subsection{Coleta de dados para simulação dos sistemas de serviço considerados}

Os dados de demanda com detalhamento de sua flutuação no decorrer do horário de atendimento, tal como apresentados na Figura 5, não estavam disponíveis e foram coletados em campo, por observação direta, num dia letivo típico. O número médio de clientes que chegam ao sistema por hora, distingue bem a biblioteca e o restaurante universitário, respectivamente, como Loja de Serviço e Serviço de Massa. Na coleta de dados de tempos de serviço e de participação dos atendentes nos processos de serviço, houve uma maior necessidade de recorrer à técnica de Amostragem do Trabalho no estudo da biblioteca. Isso se deve à diversidade de serviços oferecidos que também podem ser combinados e pela necessidade de conhecer o perfil da demanda de serviços solicitados pelo cliente. Já no estudo do restaurante universitário, a técnica mais utilizada foi a Cronometragem dos tempos das operações, pois devido ao volume muito maior de clientes e à maior padronização do serviço, o seu fluxo corre sequencialmente em etapas de ciclo curto que envolvem procedimentos bem definidos.

\subsection{Modelo computacional dos sistemas de serviço considerados}

Para a simulação de cada um dos dois tipos de serviços tomados como objeto de estudo, foram construídos dois modelos: um com o Arena e outro com o ProModel. Na programação do modelo da biblioteca foi necessário incluir os dados da probabilidade de solicitação associada a cada tipo de serviço prestado e especificar as diferentes rotas de fluxo do processo que podem ser seguidos de acordo com o(s) serviço(s) solicitado(s) pelo cliente. A fim de se obter um modelo representativo do sistema 
real, todas as alternativas relevantes de combinação de atividades foram consideradas. A modelagem tornou-se, então, complexa exigindo um esforço e tempo relativamente maiores para a programação.

Já no serviço oferecido pelo restaurante universitário, o fluxo bem definido da sequência de atividades não requereu a inclusão de tantos pontos de decisão no modelo tornando o processo de modelagem mais simples se comparado ao da biblioteca.

A programação dos modelos de simulação foi baseada nos fluxogramas dos sistemas de operação da biblioteca e do restaurante universitário apresentados no Apêndice $1 \mathrm{e}$ Apêndice 2, respectivamente. O Quadro 2 resume o modo de representação considerado na construção dos programas de simulação com o Arena e ProModel para os sistemas de serviço da biblioteca e do restaurante universitário.

No que tange à representação dos recursos humanos que trabalham como atendentes nestes sistemas, no modelo da biblioteca foram considerados como recursos flexíveis (por realizar diferentes atividades) e móveis (por ter de se movimentar entre diferentes posições dentro do sistema), enquanto que no front office do restaurante universitário
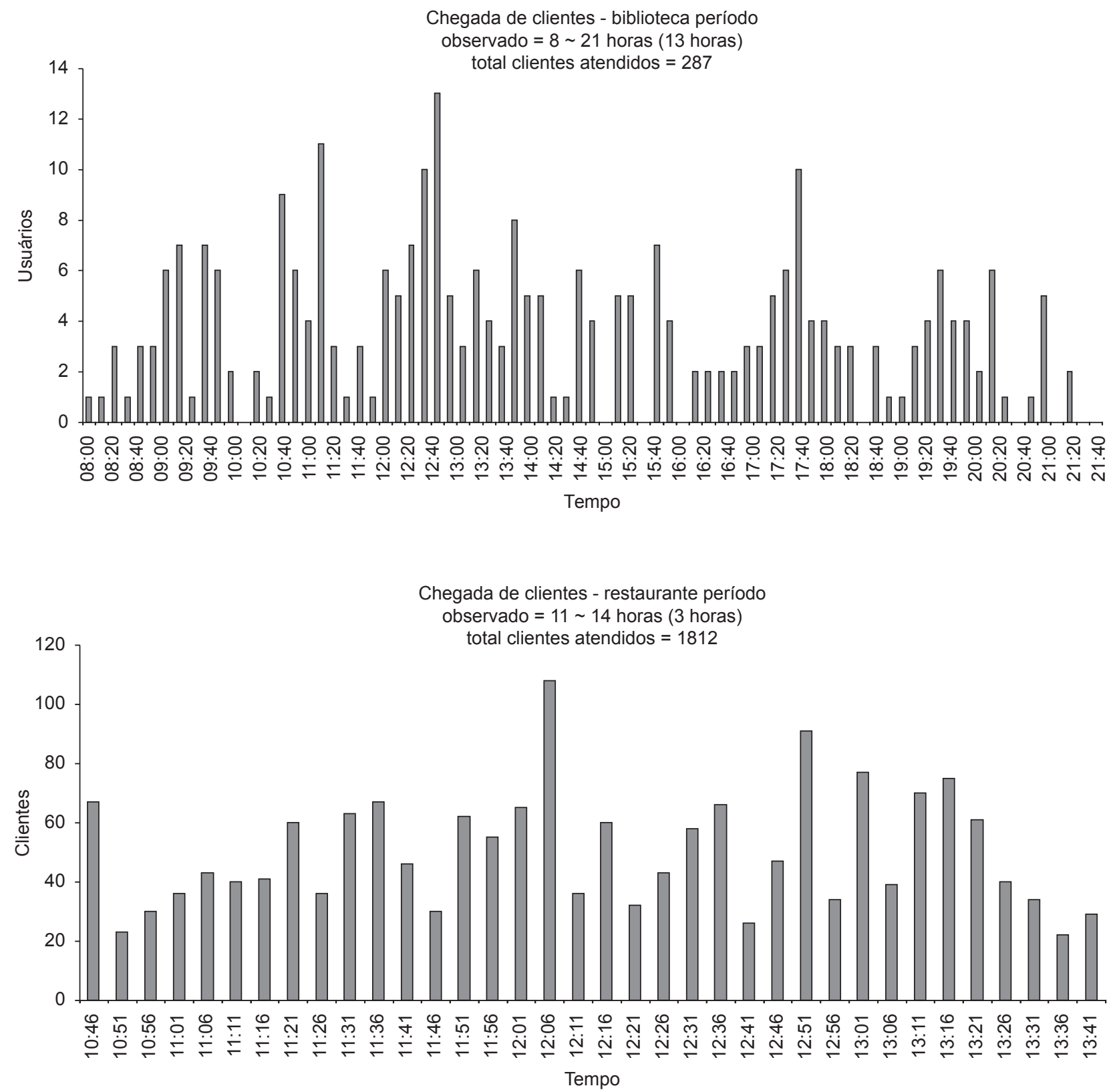

Figura 5. Chegadas de clientes na biblioteca e restaurante. 
foram admitidos como dedicados e fixos (por realizarem uma tarefa mais repetitiva num dado posto de trabalho).

A Figura 6 ilustra como os modelos dos dois sistemas de operação, tomados como objetos de estudo, foram representados para fins de animação gráfica com o ProModel. A Figura 7 apresenta uma visão parcial da forma como o fluxo de atendimento de clientes foi programado nos modelos construídos com o Arena.

\section{Análise do processo de modelagem}

Nesta seção, são discutidos os principais pontos (diferenças, particularidades) constatados no decorrer das fases do processo de modelagem dos sistemas de serviço analisados.

\subsection{Variedade de serviços}

O número de serviços oferecidos ao cliente exerce grande influência na modelagem computacional e é um bom indicativo inicial para posicionamento do serviço objeto de estudo sugerindo a complexidade do modelo a ser programado.

A representação do cliente no sistema, para fins do processo de modelagem, é mais significativa se analisada de acordo com o grau de influência do cliente na aquisição do serviço. Quanto maior a possibilidade de escolha do serviço e a liberdade do cliente no sistema, maior é a complexidade de modelagem para representar as possíveis ações e rotas (Apêndice 3 e Apêndice 4). Já a presença do cliente (remota ou física) não representa um fator muito significativo na programação do modelo.

Quadro 2. Elementos de modelagem utilizando os simuladores Arena e ProModel.

\begin{tabular}{|c|c|c|c|c|}
\hline Modelagem de & $\begin{array}{c}\text { Elementos básicos } \\
\text { de modelagem com } \\
\text { ProModel }\end{array}$ & $\begin{array}{l}\text { Painel de construção de } \\
\text { modelos com ARENA }\end{array}$ & Biblioteca & $\begin{array}{l}\text { Restaurante } \\
\text { universitário }\end{array}$ \\
\hline a) Processos & $\begin{array}{c}\text { Processing } \\
\text { Operation \& Routing } \\
\text { Destination }\end{array}$ & Process Module (Action) & $\begin{array}{l}15 \text { processos com o } \\
\text { cliente e } 4 \text { processos } \\
\text { dos atendentes }\end{array}$ & $\begin{array}{l}16 \text { processos e } 2 \\
\text { processos de atendentes }\end{array}$ \\
\hline b) Etapas de decisão & $\begin{array}{l}\text { Routing Rule \& } \\
\text { Move logic }\end{array}$ & $\begin{array}{c}\text { Decide Module \& Routel } \\
\text { Station Modules }\end{array}$ & $\begin{array}{c}39 \text { rotas e } 9 \text { blocos de } \\
\text { decisão }\end{array}$ & $\begin{array}{c}16 \text { rotas e } \\
1 \text { bloco de decisão }\end{array}$ \\
\hline c) Entidades & Entity \& Arrivals & $\begin{array}{l}\text { Create \& Entity \& } \\
\text { Schedule Modules }\end{array}$ & $\begin{array}{l}287 \text { clientes/período de } \\
\text { atendimento de } 1 \text { dia }\end{array}$ & $\begin{array}{l}1812 \text { clientes/período de } \\
\text { refeição de } 1 \text { dia }\end{array}$ \\
\hline d) Postos de Serviço & Location & Process \& Quеие Modules & $\begin{array}{c}13 \text { locais } \\
\text { (6 postos e } 7 \text { filas) }\end{array}$ & $\begin{array}{c}14 \text { locais } \\
\text { (9 postos e } 5 \text { filas) }\end{array}$ \\
\hline e) Recursos humanos & $\begin{array}{c}\text { Resources \& Path } \\
\text { Networks ou Location }\end{array}$ & Resources & $\begin{array}{c}2 \text { atendentes, } 1 \text { rede de } \\
\text { caminho para recursos } \\
\text { (ProModel) }\end{array}$ & $\begin{array}{l}1 \text { atendente na catraca, } \\
1 \text { atendente em cada balcão }\end{array}$ \\
\hline
\end{tabular}

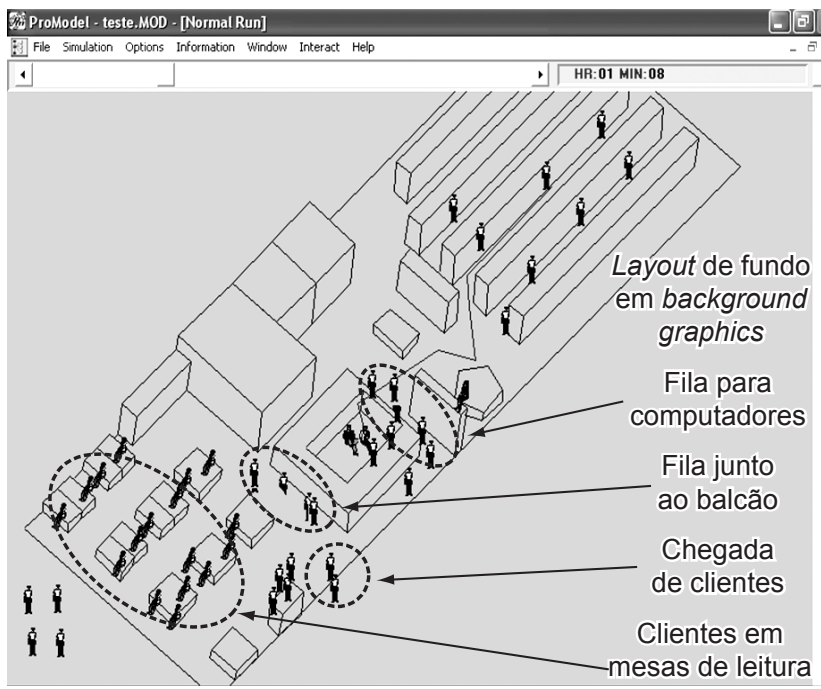

Biblioteca

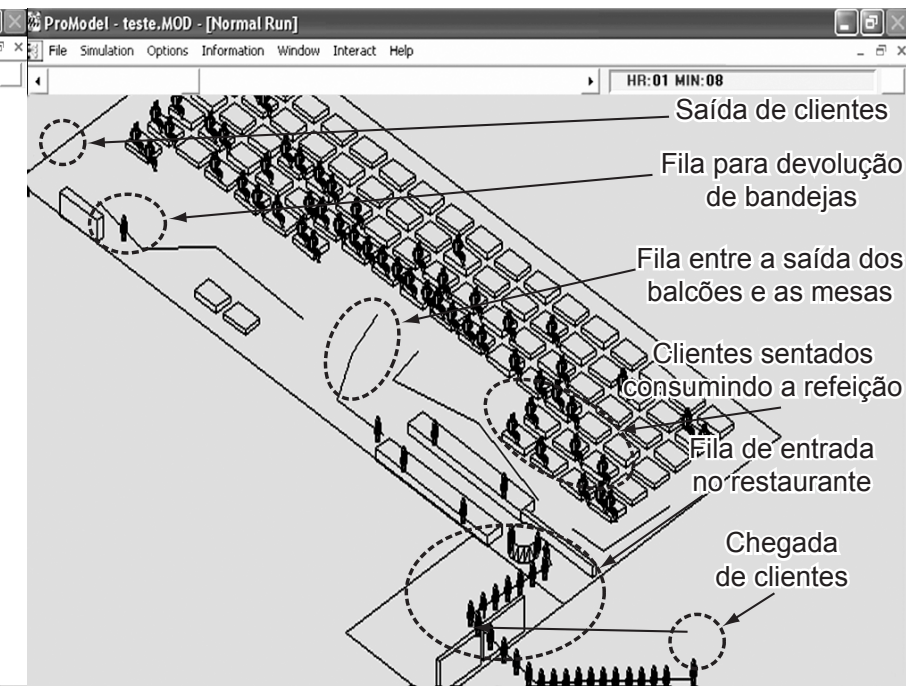

Restaurante universitário

Figura 6. Modelos de simulação construídos com ProModel. 


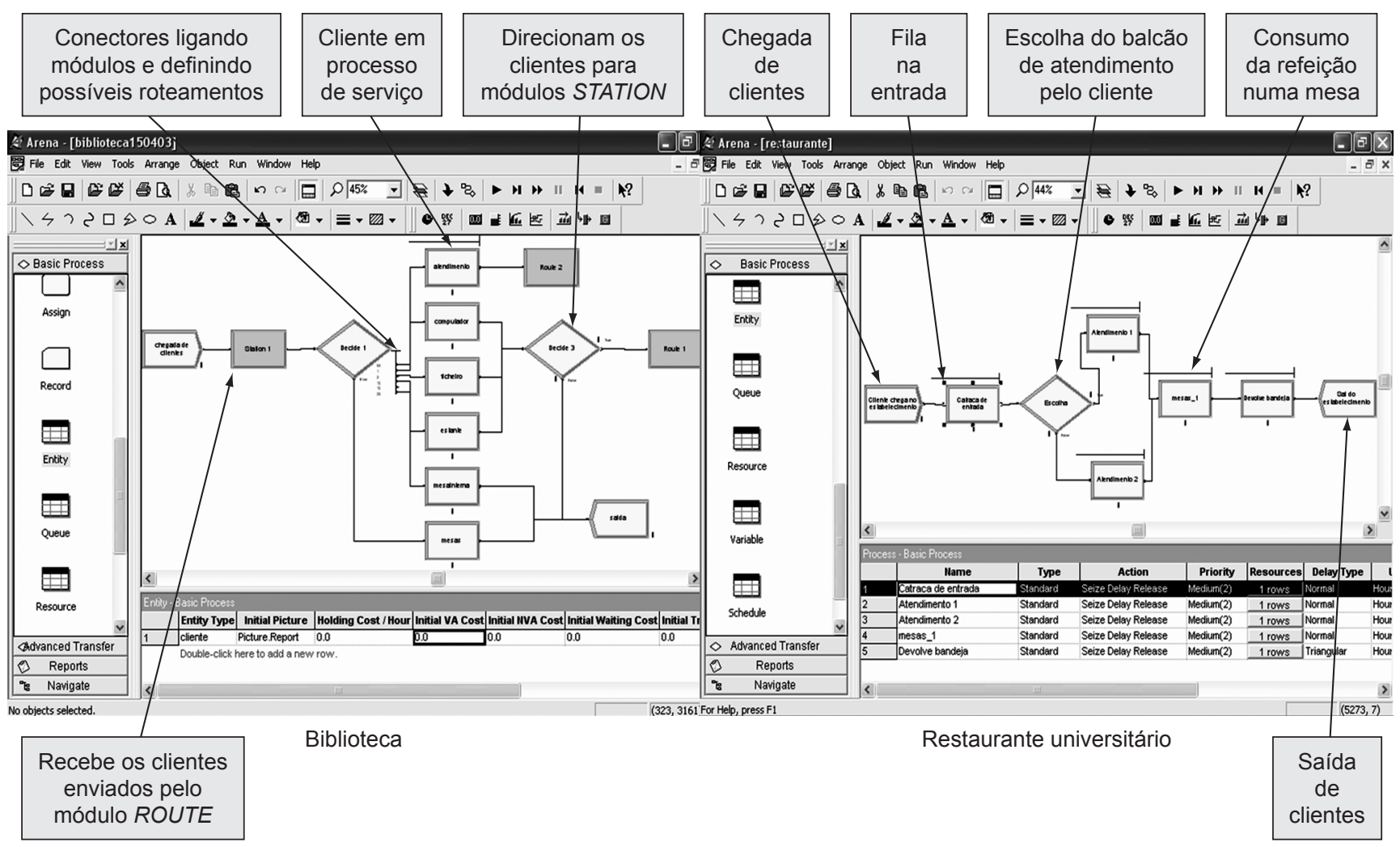

Figura 7. Modelos de simulação construídos com Arena.

\subsection{Recursos modelados}

É fundamental considerar a forma de organização dos recursos humanos, pois compreende abordagens de organização do trabalho que influenciam diretamente a estruturação do modelo de simulação. A avaliação dos simuladores aplicados na modelagem e simulação dos casos estudados evidenciou que estas ferramentas não permitem incorporar a influência de dimensões emocionais e sensoriais no comportamento humano tanto dos provedores de serviço quanto dos clientes.

A representação dos recursos humanos com abordagem de linha de produção pode ser definida como uma sequência de estações de trabalho, que realizam somente um tipo de atividade e não se movimentam no sistema. Num outro extremo, os recursos podem ser compartilhados, organizados em equipes e ter habilidades multifuncionais. No simulador ProModel, os funcionários podem ser representados como recursos vinculados a redes de caminhos que se movimentam no sistema de acordo com a solicitação do cliente. Este simulador possibilita programar atividades que demandam múltiplos recursos e assim considerar a noção de trabalho em equipe na simulação, porém assim como o Arena, não permite representar satisfatoriamente aspectos como tomadas de decisão mais complexas pelos recursos humanos e a comunicação entre entidades no sistema.

Não obstante a intangibilidade dos serviços ser uma das dimensões mais significativas do conceito de serviço, sua avaliação e representação por meio da simulação só podem ser consideradas indiretamente e de forma muito simplificada. Aspectos como cortesia, empatia, hospitalidade e clareza, bem como seus impactos no resultado do processo (ex: satisfação do cliente) são de natureza intangível e os modelos programados com os simuladores avaliados não permitem representar como a forma de sua manifestação afeta o serviço prestado.

\subsection{Fluxo de processos}

A definição dos roteamentos das entidades é um desdobramento da complexidade do fluxo de processos. Roteamentos simples resultam de fluxos bem definidos e da restrição à personalização do serviço. Por outro lado, quando há uma variedade maior de atividades que podem ser solicitadas pelo cliente, de acordo com alguma lógica, regra, atributo ou probabilidade, múltiplos roteamentos devem ser previstos. Na fase de programação, ambos os simuladores oferecem possibilidades de modelagem do roteamento para lidar com esta complexidade.

No processo de modelagem, quanto maior a influência do cliente, maior a complexidade do modelo e da sua construção dada a necessidade de programar entidades, que utilizam múltiplos recursos/estações de trabalho e escolhem seus caminhos com base nos atributos, probabilidades ou regras. Em Serviços de Massa, essa influência do cliente é reduzida e as restritas oportunidades de escolha do cliente pouco variam o curso do processo de prestação do serviço. 
7.4 Avaliação de abrangência dos simuladores

A partir dos elementos e dimensões do serviço relacionados no Quadro 1 foi definido um conjunto de requisitos fundamentais para modelagem de sistemas de operação de serviços. Na Tabela 1, a coluna "Requisitos para a modelagem" foi obtida pelo desdobramento dos itens da coluna "Natureza" referentes a cada elemento/dimensão. Buscou-se descrever, sucintamente, o que é esperado de um software de simulação para que represente bem diferentes aspectos das operações de serviço entre os extremos considerados.

O grau de atendimento destes requisitos pelo software de simulação, indica a adequação de sua aplicação na modelagem do sistema de serviço objeto de estudo. Ressalta-se, no entanto, que objetivos distintos de simulação refletem em necessidades particulares de modelagem e utilização de softwares de simulação. O quadro genérico apresentado na Tabela 1 visa fornecer uma estrutura conceitual para considerar que possibilidades de representação um simulador deveria oferecer aos modeladores para suportá-los na construção de modelos que incorporem adequadamente a natureza de sistemas de serviço. Sabe-se que, dependendo do tipo de serviço e do objetivo da simulação, alguns requisitos ganham maior peso e importância para a modelagem, enquanto outros podem até ser desconsiderados. Uma implicação disso é que podem existir softwares de simulação que embora não atendam a todos os requisitos especificados sejam avaliados satisfatoriamente pelo modelador para aplicação num estudo de simulação, por atender aos requisitos mais importantes tendo em vista os objetivos e as características do serviço a ser analisado. Por outro

Tabela 1. Requisitos para modelagem de sistemas de operação de serviços aplicados na avaliação dos simuladores Arena e ProModel.

\begin{tabular}{|c|c|c|c|c|}
\hline \multirow{2}{*}{$\begin{array}{l}\text { Elementos ou } \\
\text { dimensão }\end{array}$} & \multirow[t]{2}{*}{ Natureza } & \multirow{2}{*}{$\begin{array}{c}\text { Requisitos para a } \\
\text { modelagem }\end{array}$} & \multicolumn{2}{|c|}{ Simulador } \\
\hline & & & ProModel & Arena \\
\hline $\begin{array}{l}\text { Serviços oferecidos } \\
\text { para o cliente }\end{array}$ & Único Diversificado & $\begin{array}{l}\text { Permitir modelagem de múltiplas atividades associadas a } \\
\text { único/múltiplos recursos ou estações de trabalho }\end{array}$ & V & $\mathrm{V}$ \\
\hline \multirow[t]{7}{*}{ Cliente } & \multirow{3}{*}{$\begin{array}{l}\text { Presença do cliente } \\
\text { no sistema (in loco } \sim \\
\text { remota) }\end{array}$} & $\begin{array}{l}\text { Possibilitar a movimentação (roteamento) da entidade } \\
\text { (pessoas ou coisas) no sistema }\end{array}$ & $\mathrm{V}$ & $\mathrm{V}$ \\
\hline & & $\begin{array}{l}\text { Definição de tempos, velocidade, distâncias, sequências } \\
\text { de atendimento }\end{array}$ & V & V \\
\hline & & $\begin{array}{l}\text { Definição do comportamento dos eventos (demanda) no } \\
\text { sistema }\end{array}$ & $\mathrm{V}$ & $\mathrm{V}$ \\
\hline & \multirow{4}{*}{$\begin{array}{l}\text { Influência no proces- } \\
\text { so (baixa influência } \\
\text { alta influência) }\end{array}$} & Programar atributos nas entidades & $\mathrm{V}$ & $\mathrm{V}$ \\
\hline & & Criar serviços padronizados para o cliente & $\mathrm{V}$ & $\mathrm{V}$ \\
\hline & & $\begin{array}{l}\text { Probabilidade de escolha dos serviços; Roteamento } \\
\text { múltiplo }\end{array}$ & $\mathrm{V}$ & $\mathrm{V}$ \\
\hline & & $\begin{array}{l}\text { Considerar fidelização do cliente e sua influência no pro- } \\
\text { cesso de prestação do serviço }\end{array}$ & $\mathrm{N}$ & $\mathrm{N}$ \\
\hline \multirow{7}{*}{$\begin{array}{l}\text { Organização dos } \\
\text { recursos humanos }\end{array}$} & \multirow[t]{3}{*}{ Linha de Produção } & Recursos dedicados, especialização de tarefas & $\mathrm{V}$ & $\mathrm{V}$ \\
\hline & & Definição de critérios para atendimento do cliente & $\mathrm{V}$ & $\mathrm{V}$ \\
\hline & & $\begin{array}{l}\text { Definição de ritmo de trabalho, paradas, turnos de traba- } \\
\text { lho dos recursos }\end{array}$ & $\mathrm{V}$ & $\mathrm{V}$ \\
\hline & \multirow{4}{*}{$\begin{array}{l}\text { Organização baseada } \\
\text { em times }\end{array}$} & Compartilhamento dos recursos em diferentes atividades & $\mathrm{V}$ & $\mathrm{V}$ \\
\hline & & $\begin{array}{l}\text { Definir decisões e objetivos aos elementos do modelo } \\
\text { (recursos e pessoas) }\end{array}$ & $\mathrm{N}$ & $\mathrm{N}$ \\
\hline & & Representar formação de times & $\mathrm{V}$ & $\mathrm{P}$ \\
\hline & & Permitir comunicação entre recursos/entidades do modelo & $\mathrm{N}$ & $\mathrm{N}$ \\
\hline $\begin{array}{l}\text { Ênfase das } \\
\text { operações }\end{array}$ & $\begin{array}{l}\text { Back office/Front } \\
\text { office }\end{array}$ & $\begin{array}{l}\text { Permitir modelagem de atividades no front office e no } \\
\text { back office }\end{array}$ & $\mathrm{V}$ & $\mathrm{V}$ \\
\hline Volume de clientes & Unidades $\sim$ milhares & Definição dos eventos gerados (demanda) no sistema & $\mathrm{V}$ & V \\
\hline \multirow[t]{2}{*}{ Intangibilidade } & Objetiva & $\begin{array}{l}\text { Percepção de espera; qualificação dos recursos; consistên- } \\
\text { cia do serviço }\end{array}$ & $\mathrm{N}$ & $\mathrm{N}$ \\
\hline & Perceptiva & Atendimento; atmosfera; segurança; confiança & $\mathrm{N}$ & $\mathrm{N}$ \\
\hline $\begin{array}{l}\text { Simultaneidade/ } \\
\text { perecibilidade }\end{array}$ & $\begin{array}{l}\text { Ocorrência } \\
\text { de filas/ espera }\end{array}$ & $\begin{array}{l}\text { Programação e definição de locais de formação de filas; } \\
\text { Geração de relatórios relacionados à fila }\end{array}$ & $\mathrm{V}$ & $\mathrm{V}$ \\
\hline Variabilidade & Sistema estocástico & $\begin{array}{l}\text { Utilizar tempos estocásticos ou de acordo com funções } \\
\text { que consideram os atributos das entidades ou variáveis do } \\
\text { sistema }\end{array}$ & $\mathrm{V}$ & V \\
\hline
\end{tabular}

$\mathrm{V}=$ Verificado; $\mathrm{N}=$ Não verificado; $\mathrm{P}=$ Parcialmente verificado. 
lado, um software que atende a todos os requisitos para modelagem, pelo critério apresentado neste trabalho, pode ser considerado um software de simulação bastante flexível para modelagem de diferentes Lojas de Serviços e Serviços de Massa.

Vale ressaltar que a Tabela 1 não esgota todos os elementos/dimensões que devem ser considerados na caracterização do modelo conceitual de um serviço, ou seja, a abrangência da coluna "Requisitos para a modelagem" não prevê toda a complexidade possível das organizações de serviços. Porém, fornece uma referência básica para avaliação de softwares de simulação que possam ser aplicados na representação e simulação de sistemas de operação de serviços.

Os simuladores aplicados na programação dos modelos da biblioteca e do restaurante universitário foram avaliados à luz desses requisitos de modelagem e constatou-se que não atendem a todos os requisitos relacionados para modelagem de serviços. Dos 21 requisitos avaliados, estes simuladores atenderam a cerca de $70 \%$ dos elementos de serviços (Tabela 2).

No entanto, os itens não verificados representam condições ou efeitos importantes num sistema de serviço, tais como a fidelização do cliente, tomadas de decisão com base em critérios subjetivos pelos clientes/atendentes, comunicação informal entre os agentes envolvidos durante o processo e as implicações dos aspectos intangíveis na dinâmica do serviço. Apesar dos simuladores analisados apresentarem qualidades muito semelhantes de atendimento desses requisitos, isso não significa que os esforços de modelagem com sua aplicação sejam semelhantes. Mesmo que a representação de um elemento ou dimensão tenha sido verificada como sendo possível com o uso de qualquer destes simuladores, o tempo para modelagem pode ser mais longo ou curto dependendo do simulador escolhido.

Além dos requisitos para gerar modelos bastante representativos dos sistemas de operação de serviços que sejam objetos de estudo, espera-se que o software de simulação também ofereça funções para facilitar a tarefa de construção do modelo e a sua respectiva Verificação. Essas funções não se destinam somente à modelagem de serviços, mas auxiliam e agilizam a modelagem de uma forma geral na especificação de parâmetros, disponibi-

Tabela 2. Resumo dos requisitos de modelagem de sistemas de serviços atendidos.

\begin{tabular}{lccc}
\hline Simulador & Verificado & $\begin{array}{c}\text { Não } \\
\text { verificado }\end{array}$ & $\begin{array}{c}\text { Parcialmente } \\
\text { verificado }\end{array}$ \\
\hline Arena & 15 & 5 & 1 \\
& $71 \%$ & $24 \%$ & $5 \%$ \\
ProModel & 16 & 5 & 0 \\
& $76 \%$ & $24 \%$ & $0 \%$ \\
\hline
\end{tabular}

lização de ferramentas de correção de erros (debugger), facilidade de verificação do comportamento do modelo na simulação, entre outras. A visualização gráfica da modelagem favorece a construção do modelo, tornando a interface máquina/modelador mais simples e intuitiva (user-friendly). As principais funções de suporte que facilitaram a construção de modelos para os dois sistemas de operação tomados como objetos de estudo estão indicadas no Quadro 3. A maioria delas não é oferecida pelos pacotes do tipo linguagem de simulação. Para o modelador, essas funções inseridas em um único "pacote" diminuem o tempo gasto no tratamento de dados de entrada e relatórios de saída.

O Quadro 3 sugere que os dois simuladores analisados oferecem funções de suporte ao processo de modelagem semelhantes. Isso reflete uma preocupação dos fabricantes de softwares de simulação em facilitar e popularizar o uso da simulação agilizando a construção do modelo. Vale ressaltar que a comparação realizada não teve como propósito evidenciar a superioridade de um software em relação ao outro; buscou-se oferecer apenas uma orientação sobre quais os elementos de sistemas de operações de serviço podem ser representados com maior facilidade por simuladores de eventos discretos disponíveis no mercado.

\section{Conclusões}

A Figura 8 sintetiza os principais elementos/dimensões a serem observados ao longo das três fases do processo de modelagem de sistemas de operação de serviços. Embora os Serviços Profissionais não tenham sido analisados neste trabalho, a figura sugere como esta categoria de serviço se posicionaria no contexto de variação dos elementos/dimensões considerados.

Este trabalho fornece uma relação de requisitos para avaliar em que medida um software de simulação satisfaz as necessidades de modelagem de sistemas de operação de serviços do tipo Lojas de Serviços ou Serviços de Massa.

Considerando estes requisitos para a modelagem de serviços, os resultados evidenciaram que existem aspectos que não são representados satisfatoriamente pelos simuladores analisados, em especial, os elementos perceptivos (intangíveis) que compõem o conceito de serviço. Apesar disso, não se pode concluir que os simuladores de eventos discretos avaliados não são adequados para modelagem de serviços, pois a adequação do software de simulação depende principalmente dos objetivos da simulação. Caso o objetivo principal de um estudo de simulação seja, por exemplo, avaliar o nível de serviço oferecido aos clientes em termos de rapidez no atendimento, verificar a eficiência na utilização de recursos ou prever o impacto da variação da demanda nas filas - preocupações típicas dos gestores 
de operações e projetistas de Serviços de Massa ou Lojas de Serviço - ambos os simuladores analisados atendem de forma bastante satisfatória às necessidades do estudo, pois oferecem facilidades que suportam tais análises.
Nos últimos anos, a Simulação Baseada em Agentes (SBA) emergiu como uma nova abordagem de simulação computacional que oferece possibilidades interessantes de incorporar a representação de fatores humanos nos modelos.

Quadro 3. Funções de suporte ao processo de modelagem aplicados na análise dos simuladores Arena e ProModel.

\begin{tabular}{|c|c|c|c|}
\hline \multirow{9}{*}{$\begin{array}{l}\text { Funções de suporte } \\
\text { ao processo de } \\
\text { modelagem }\end{array}$} & & \multicolumn{2}{|c|}{ Simulador } \\
\hline & & ProModel & Arena \\
\hline & Modelagem gráfica & Drag-and-drop; locations, path network & Drag-and-drop; módulo \\
\hline & Verificação de modelos & Debugger; rastreamento & $\begin{array}{l}\text { Debugger com levantamento de } \\
\text { possíveis causas do problema }\end{array}$ \\
\hline & $\begin{array}{l}\text { Ajuste estatístico de } \\
\text { dados de entrada }\end{array}$ & Stat-fit & Input analyser \\
\hline & $\begin{array}{l}\text { Análise estatística de } \\
\text { dados de saída }\end{array}$ & Output results & Output analyser \\
\hline & Templates reutilizáveis & Submodels; Merge submodels & Submodels; Copy-paste \\
\hline & Recursos de animação & Edição de imagem; importação & Edição de imagem; importação \\
\hline & $\begin{array}{l}\text { Visualização em } \\
\text { tempo real }\end{array}$ & Não dispõe desse recurso & $\begin{array}{c}\text { Real-time simulation; comunicação } \\
\text { com sistemas externos }\end{array}$ \\
\hline
\end{tabular}

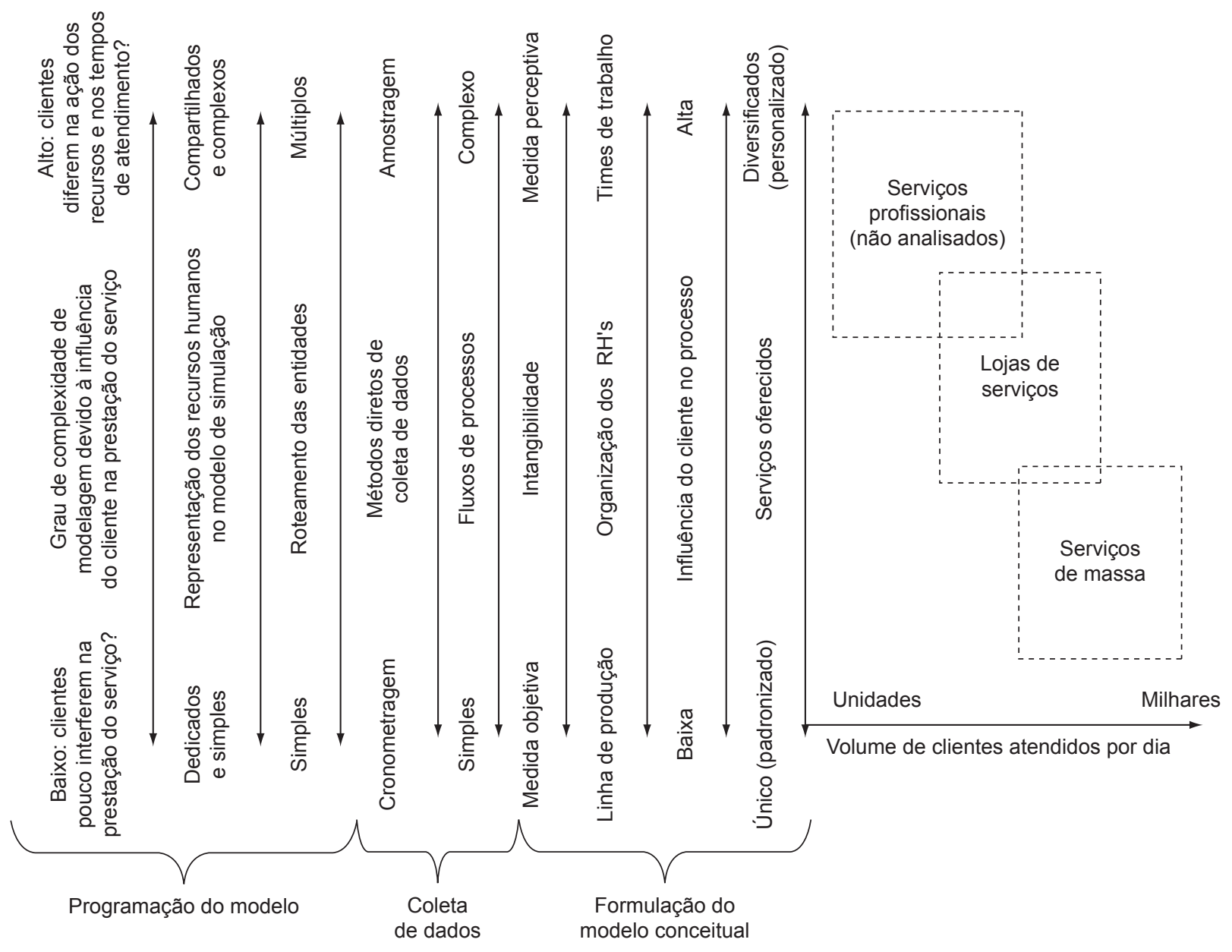

Figura 8. Análise do processo de modelagem de sistemas de operação de serviços. 
A SBA - considerada por Macal e North (2005) como um novo paradigma de modelagem - é uma modalidade de simulação que se distingue por possibilitar a definição de entidades autônomas (agentes) que possuem determinados objetivos no sistema, além da capacidade de adaptar seu comportamento de acordo com sua evolução e interação com o ambiente e outros agentes. Isto requer uma forma de memória e flexibilidade para modificar suas próprias regras de comportamento (Borshchev e Filippov, 2004). Segundo Taylor et al. (2004), em ambientes complexos sempre existirão decisões de operação realizadas por pessoas. Portanto, as capacidades de representação, modelagem e análise do comportamento e inteligência humana são requisitos desejados para o futuro da modelagem e simulação de serviços em que a possibilidade de analisar as implicações do comportamento humano em maior profundidade seria altamente desejável. A SBA oferece grandes possibilidades de contribuição nesse campo e desponta como um importante tema para a realização de pesquisas futuras sobre o desenvolvimento de tecnologias que suportem a aplicação da simulação no estudo de sistemas de serviços.

\title{
Application of discrete event simulation in service industry modeling processes
}

\begin{abstract}
This work discusses the simulation modeling process applied in two types of service operation systems: Services Shops and Mass Services. An issue considered in this study is related to the requirements simulation software tools should fulfill in order to be applicable in the process of building service system simulation models. To analyze the differences in modeling process depending on the type of service considered, two simulators were selected. This study brought to light that the computer technology and simulation software tools still need to go through further developments so that their application can be extended to the modeling and simulation of a broader range of features comprised by service systems in general, which distinguish them from manufacturing systems.
\end{abstract}

Keywords: Service. Discrete event simulation. Modeling process.

\section{Referências bibliográficas}

BANKS, J.; CARSON, J.; NELSON, B. Discrete-event system simulation. New Jersey: Prentice Hall, 1996.

BORSHCHEV, A.; FILIPPOV, A. From system dynamics and discrete event to practical agent based modeling: reasons, techniques, tools. In: INTERNATIONAL CONFERENCE OF THE SYSTEM DYNAMICS SOCIETY, 22, 2004. Proceedings... Oxford, England: Keble College, 2004.

BOWEN, D. E.; LAWLER III, E. E. Organizing for service: empowerment or production line? In: Understanding Services Management. England: John Wiley \& Sons, 1995.

CORRÊA, H. L.; CAON, M. Gestão de serviços: lucratividade por meio de operações e satisfação dos clientes. São Paulo: Atlas, 2002.

FITZSIMMONS, J. A.; FITZSIMMONS, M. J. Administração de serviços: operações, estratégias e tecnologia de informação. 2 ed. Porto Alegre: Bookman, 2000.

GIACHETTI, R. et al. Assessing the viability of an open access policy in an outpatient clinic. In: WINTER SIMULATION CONFERENCE, 2005, Florida. Disponível em: <http://www. informs-cs.org/wsc05papers/282.pdf>. Acesso em: 12 Fev.2009.

GIANESI, I. G. N.; CORRÊA, H. L. Administração estratégica de serviços. São Paulo: Atlas, 1994.
GORDON, G. System simulation. 2 ed. New Jersey: Prentice Hall, 1978.

JOHNSTON, R.; CLARK, G. Administração de operações de serviço. São Paulo: Atlas, 2002.

KLUNGLE, R. Simulation of a claims call center: a success and a failure. In: WINTER SIMULATION CONFERENCE, 1999, Arizona. Disponível em: <http://www.informs-cs.org/ wsc99papers/prog99.html>. Acesso em: 12 Fev. 2009.

KOTLER, P. Administração de marketing. 10 ed. São Paulo: Prentice Hall, 2000.

LAW, A. M.; KELTON, W. D. Simulation modeling and analysis. 2 ed. New York: McGraw-Hill, 1991.

LOVELOCK, C. H. Services marketing. 3 ed. New Jersey: Prentice Hall, 1996.

MACAL, C. M.; NORTH, M. J. Tutorial on agent-based modeling and simulation. In: WINTER SIMULATION CONFERENCE, 2005, Florida. Disponível em: <http://www.informs-cs.org/ wsc05papers/002.pdf>. Acesso em: 12 Fev. 2009.

MACHUCA, J. A. D.; GONZÁLES-ZAMORA, M. M.; AGUILAR-ESCOBAR, V. G. Service operations management research. Journal of Operations Management, v. 25, n. 3, p. 585-603, 2007. 
PIDD, M. Modelagem empresarial: ferramentas para tomada de decisão. Porto Alegre: Artes Médicas Sul, 1996.

RIVETT, P. Model building for decision analysis. New York: J. Wiley, 1980.

SALTZMAN, R.; VIJAY, M. A call center uses simulation to drive strategic change. Interfaces, v. 31, n. 3, p. 87-101, 2001.

SASSER, W. E.; OLSEN, R. P.; WYCKOFF, D. D. Management of service operations. Boston: Allyn and Bacon, 1978.

SHAFER, S. M.; SMUNT, T. L. Empirical simulation studies in operations management: context, trends and research opportunities. Journal of Operations Management, v. 22, n. 4, p. 345-354, 2004.

SHANNON, R. E. Systems Simulation: The Art and the Science. New Jersey: Prentice-Hall, 1975.

SHOSTACK, G. L. Service positioning through structural change. Journal of Marketing, v. 51, n. 51, p. 34-43, 1987.

SIEBERS, P. et al. Understanding retail productivity by simulating management practices. In: EUROSIM, 2007, Slovenia. Disponível em: <http://eprints.nottingham. ac.uk/591/1/07eurosim_agents.pdf>. Acesso em: 12 Fev.2009.
SILVESTRO, R. Positioning services along the volume-variety diagonal. International Journal of Operation \& Production Management, v. 19, n. 4, p. 399-420, 1999.

SLACK, N. et al. Administração da produção. São Paulo: Atlas, 1997.

TANIR, O.; BOOTH, R. J. Call center simulation in Bell Canada. In: WINTER SIMULATION CONFERENCE, 1999, Arizona. Disponível em: <http://www.informs-cs.org/wsc99papers/237. pdf>. Acesso em: 12 Fev. 2009.

TAYLOR, S. J. E. et al. Panel on future challenges in modeling methodology. In: WINTER SIMULATION CONFERENCE, 2004, Washington. Disponível em: <http://www.informs-cs. org/wsc04papers/039.pdf>. Acesso em: 12 Fev. 2009.

WHITE Jr., P. A survey of data resources for simulating patients flows in the healthcare delivery systems. In: WINTER SIMULATION CONFERENCE, 2005, Florida. Disponível em: $<$ http://www.informs-cs.org/wsc05papers/109.pdf>. Acesso em: 12 Fev. 2009.

WINSTON, W. L. Operations research: applications and algorithms. 3 ed. California: Duxbury Press, 1993. 


\section{Apêndice}

Fluxo de clientes

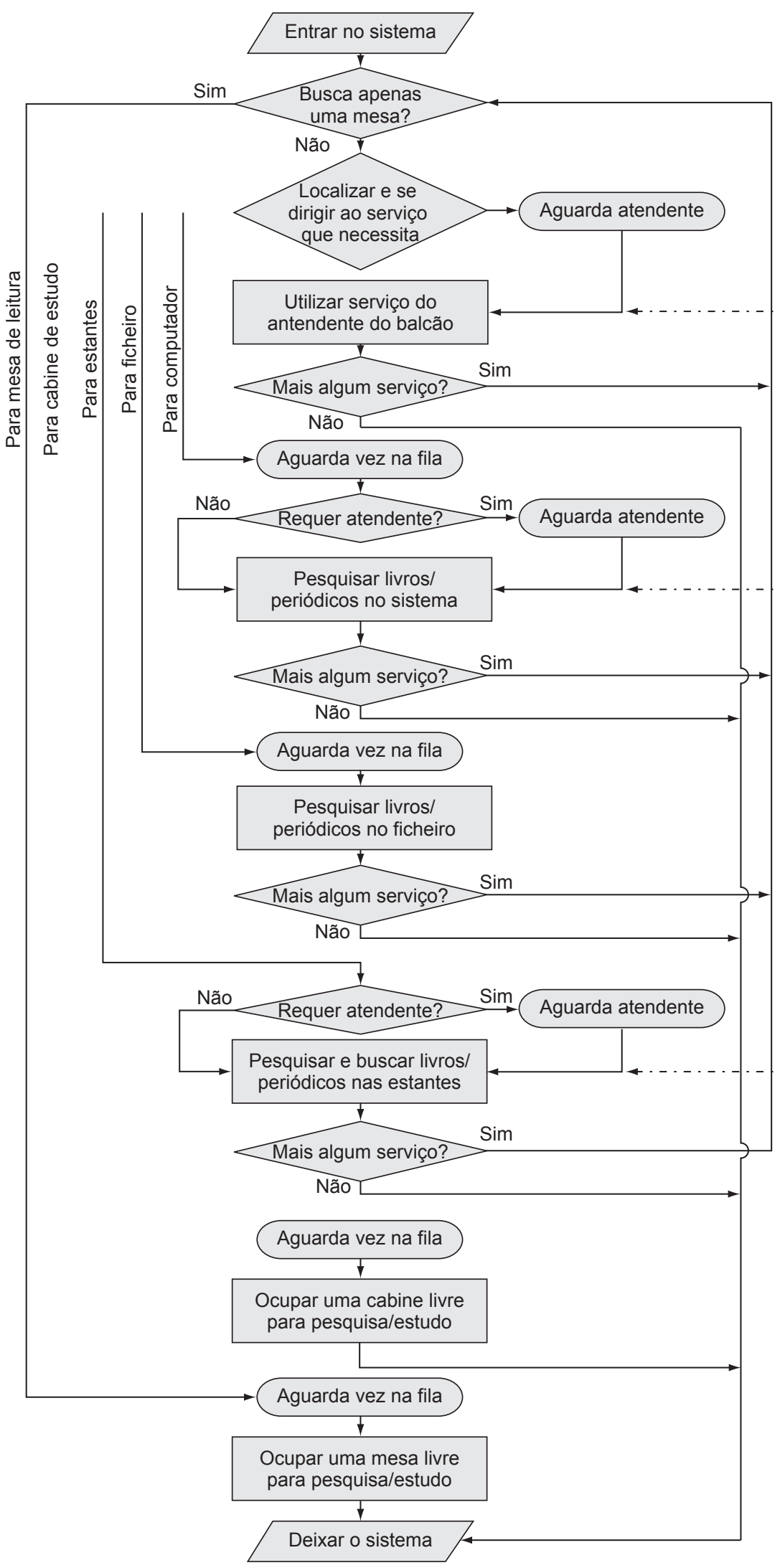

Fluxos de antendentes (2)

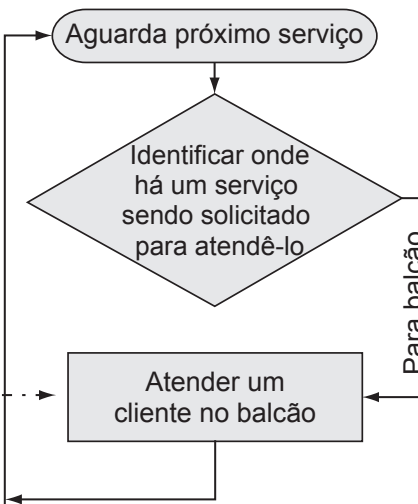

Atender cliente num computador

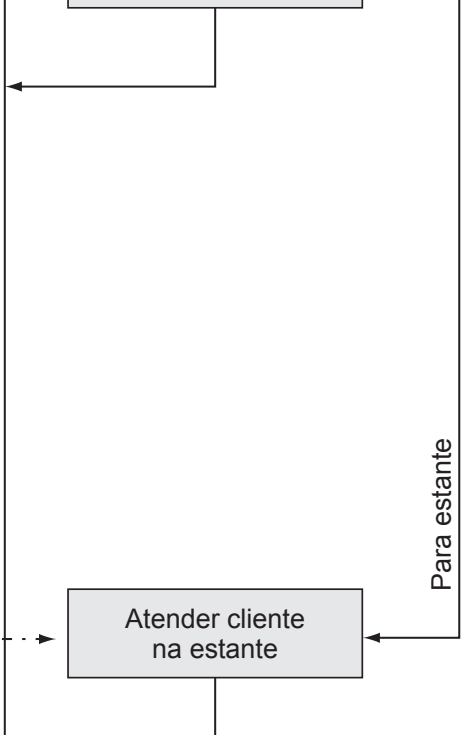

Apêndice 1. Fluxograma do sistema de operação do serviço da biblioteca. 


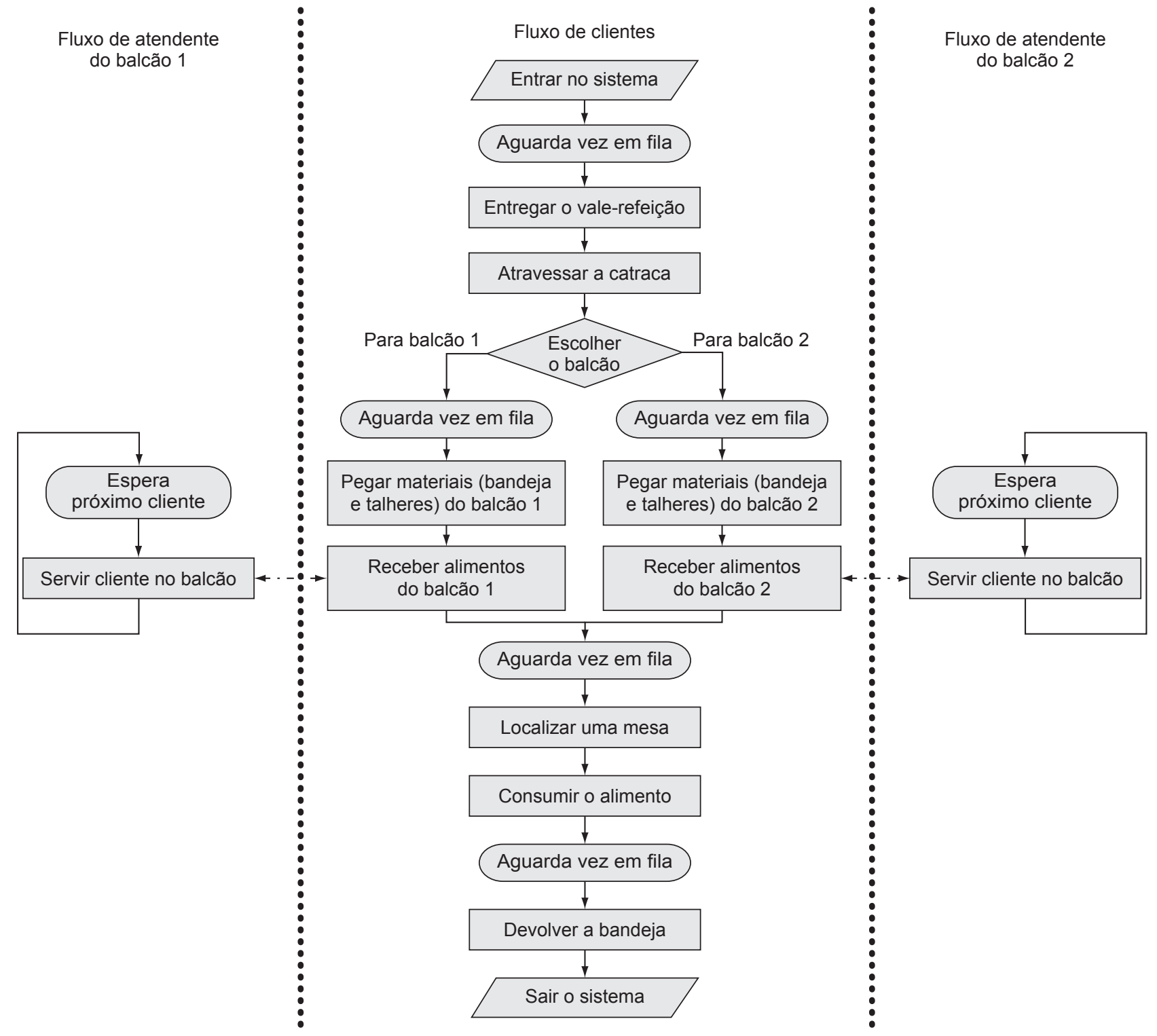

Apêndice 2. Fluxograma do sistema de operação do serviço do restaurante universitário. 


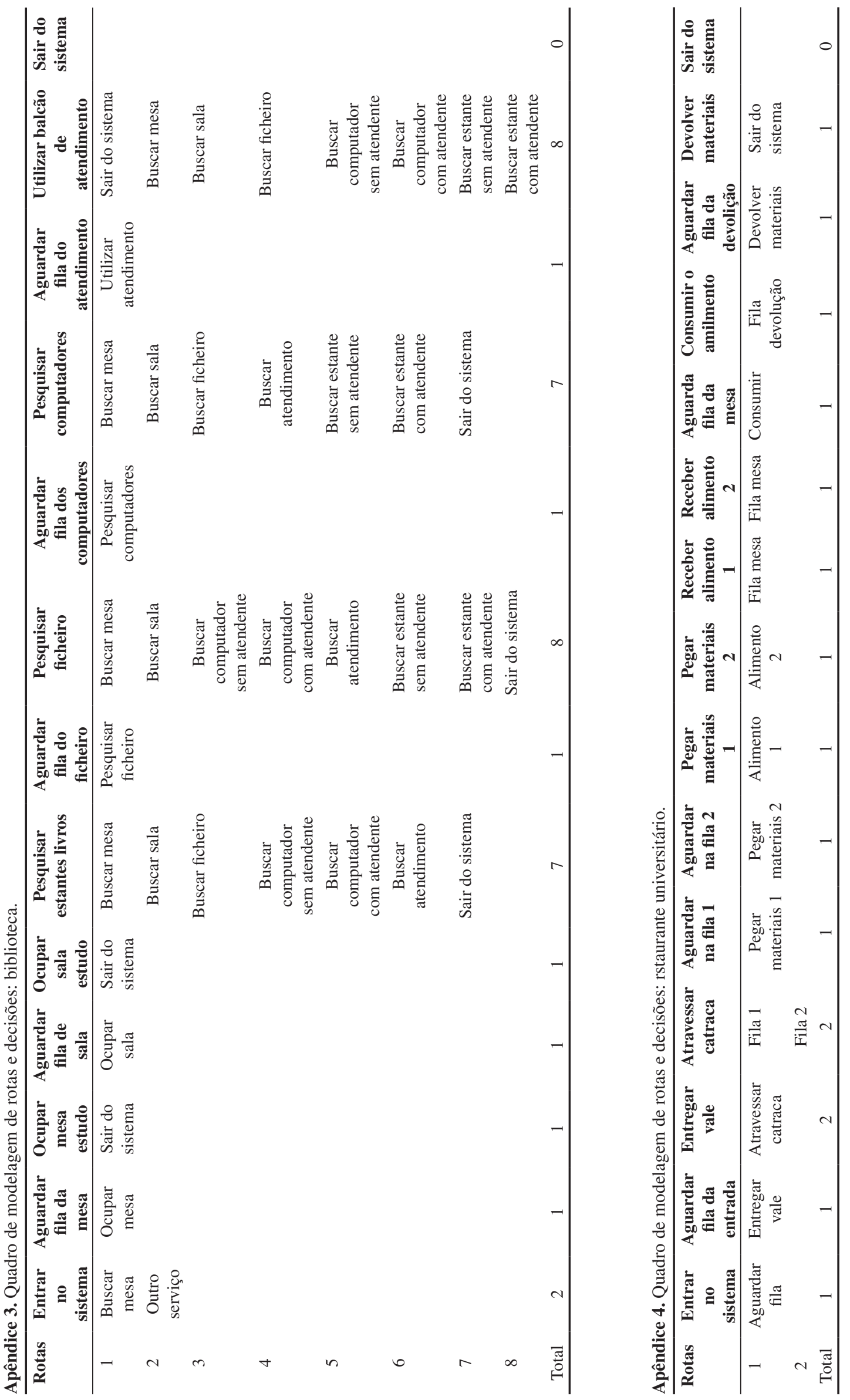




\section{Sobre os autores}

\section{Nelson Sakurada}

\section{Dario Ikuo Miyake}

Departamento de Engenharia de Produção, Escola Politécnica, Universidade de São Paulo - USP,

Av. Prof. Almeida Prado trav. 2,128, Cidade Universitária, São Paulo, SP, CEP 05508-900,

e-mails: nsakurada@uol.com.br; dariomiy@usp.br

Agradecimentos: Ao CNPq - Conselho Nacional de Desenvolvimento Científico e Tecnológico - pelo apoio e financiamento da pesquisa.

Recebido em 1/11/2006 Aceito em 11/2/2009 